Vol 11, Issue 6, 2018

\title{
MEDICINAL PLANTS AS POTENTIAL SOURCE OF ANTIOXIDANT AGENTS: A REVIEW
}

\author{
ZEENAT AYOUB*, ARCHANA MEHTA
}

Department of Botany, Laboratory of Molecular Biology, Dr. Harisingh Gour Vishwavidyalaya (A Central University), Sagar - 470003, Madhya Pradesh, India. Email: Zeenatlone2011@gmail.com

Received: 11 November 2017, Revised and Accepted: 12 January 2018

ABSTRACT

All over the world, the recent scientific studies revealed the medicinal properties of plants, which have been examined, because of their effective pharmacological activities, economic viability, and their low toxicity. Reactive oxygen species (ROS) enhancement by endogenous and exogenous stimuli can modify redox circumstances of normal cells. To balance ROS-mediated cellular damage, endogenous antioxidants' protection system subsists; however, when oxidation surpasses the control mechanisms, oxidative stress increases. Detrimental alterations induced in a variety of biomolecules such as proteins, lipids, and DNA which causes chronic escalation of oxidative stresses, which ultimately causes tissue damage and results in numerous diseases. Antioxidants reduce the effects of ROS and help us in the prevention of such diseases. Antioxidants can either be natural or synthetic. Natural antioxidants can be obtained through diet in the form of fruits, spices, vegetables, etc. Synthetic antioxidants such as butylated hydroxytoluene and butylated hydroxyanisole also diminish oxidation, but they have been proved to be dangerous to humankind; therefore, investigation for non-toxic antioxidants has increased in the recent years.

Keywords: Antioxidants, Free radicals, Medicinal plants, Phytochemicals.

(C) 2018 The Authors. Published by Innovare Academic Sciences Pvt Ltd. This is an open access article under the CC BY license (http://creativecommons. org/licenses/by/4. 0/) DOI: http://dx.doi.org/10.22159/ajpcr.2018.v11i6.24725

\section{INTRODUCTION}

\section{Antioxidants}

Antioxidants are the compounds that stop or reduce the oxidation of other compounds. A typical definition of oxidation is the amalgamation of any compound or constituent with that of oxygen. For this reason, the term oxidation comes. It originates from the French word oxider, coined by Guyton de Morveau and Antoine Lavoisier in 1787 from the words oxygene and acide. These two words, i.e., oxygene and acide were united to form the single word oxide. The processes such as oxidation and reduction that is gain of oxygen and loss of oxygen, respectively, take place concurrently, and therefore, the reaction is said to be redox reaction. The term oxide has various meanings on the basis of different scientific areas [1].

Antioxidants are naturally found in foods but in very low concentrations. Hence, to control the oxidation, supplementary amount is added to recover the whole quality and to increase life period by a mechanism known as free radical termination [2]. In human body, various processes involving biochemical and physiological activities generate by-products in the form of oxygen-centered free radicals and reactive oxygen species (ROS), which in higher amounts results in the oxidative harm to biomolecules such as carbohydrates, proteins, lipids, and DNA. Ultimately, many chronic diseases may arise [3]. Antioxidants also give protection from harm originated by abandoned ROS production and associated lipid peroxidation (LPO), breakage of deoxyribonucleic acid strand, and protein damage [4]. At physiologically virtual levels, a perfect antioxidant has to be freely absorbed, chelate metal redox and quench free radicals [5].

Free radicals are associated with the development of a number of chaos in human body such as cell death, tissue damage, atherosclerosis, arthritis, cancer, injury of central nervous system, cardiovascular diseases, obesity, and ischemic heart diseases. To get rid of such diseases of free radicals, antioxidants are needed which can protect the individual life [6]. Shortage of antioxidants, which are able to reduce or quench the free radicals, supports the progression of degenerative diseases, such as neurodegenerative diseases, for example, Alzheimer's disease, cardiovascular diseases, for example, cancers, and inflammatory diseases [7].
Antioxidants played a significant role in health defensive mechanisms. Methodical indication recommends that antioxidants diminish the risk for chronic diseases such as cancer and heart diseases. The whole grains, fruits, and vegetables are the major sources of naturally producing antioxidants. The antioxidants such as phenolic acids, carotenes, Vitamin $\mathrm{C}$, and Vitamin E obtained from plants have been documented to have the capability to decrease the risk of diseases [8]. Synthetic antioxidants such as butylated hydroxyanisole (BHT), BHT, tert-butylhydroquinone (TBHQ), and propyl gallate (PG) from food were used extensively. Chelators are also used widely because of the pro-oxidant consequences of transition metal ions including copper, magnesium, and iron in the food-producing industries. Concerning the well-being of certain man-made antioxidants as latent carcinogens, there has been sturdy concern and debate for many years. These synthetic antioxidants were still stay on the list of generally recognized as safe, but drawbacks of their use have been employed in United States, whereas BHT, TBHQ and PG at a standstill require sanction in various states. Consequently, there is emergent significance by food industry and the users in replacing these man-made antioxidants with alternatives of naturally produced substances that have been supposed to be harmless and have extensive purchaser acceptance [2], and the curiosity to utilize natural antioxidants has been increased worldwide.

Plants have been regarded as the primary source of secondary metabolites showing fascinating biological actions. Normally, these chemical constituents are the chief sources of a number of structural preparations and properties [9]. Well-known examples of these secondary metabolites involve phenols, flavonoids, phenolic glycosides, cyanogenic glycosides, and saponins [10]

Worldwide, the recent scientific studies revealed the medicinal properties of plants, which have been examined, because of their effective pharmacological activities, economic viability, and their low toxicity [11]. For many years, natural products particularly plants are being utilized for the curing of a number of diseases. From pre-historic times, terrestrial plants were used in India, China, Greece, and Egypt and a remarkable number of fresh medicines were isolated from them. The uses of medicinal plants in written records have been reported 
from the Sumerians and Alkaidians in about 2600 BC [12]. According to the World Health Organization, it has been estimated that $80 \%$ of the world's population depend on folklore medicine for their chief healthcare necessities and this remedy mostly involves the extracts from plants and the bioactive constituents present in them [13].

There is growing tendency in comparing the phytochemicals obtained from medicinal plants and their pharmacological actions. Recently, it has been reported that the natural antioxidants from therapeutic plants defend from lethal and detrimental consequences of free radicals. The antioxidants have broad range of pharmacological activities such as anti-allergic, antimutagenic, antimicrobial, anticarcinogenic, and free radical antioxidant scavenging activity $[5,14]$.

\section{SOME ASSAY METHODS USED TO ESTIMATE ANTIOXIDANT CONTENT PRESENT IN NATURAL PRODUCTS}

Antioxidants, such as phenolic compounds (phenolic acids, flavonoids, and tannins), showed wide range of biological properties, including anticarcinogenic, anti-inflammatory, and anti-atherosclerotic effects, because of their antioxidant activity [15]. Although numerous assays are available to find out the antioxidant activity. Some reported methods include 1,1-diphenyl-2-picrylhydrazine (DPPH) radical scavenging assay, 1,1-diphenyl-2-picrylhydrazine (DPPH) radical scavenging activity [16], ferric reducing antioxidant power assay [17], oxygen radical absorbance capacity assay [18], total radical trapping antioxidant potential assay [19], LPO method [20], superoxide anion scavenging activity [21], 2,2_-azinobis(3-ethylbenzthiazoline-6-sulfonic acid) (ABTS) radical scavenging method [22,23], hydroxyl radical scavenging activity [24,25], reducing power assay [26], thiobarbituric acid method [27], and Folin-Ciocalteu (FTC) method [28].

Among all the methods available to evaluate antioxidant activity, DPPH and ABTS methods are found to be most common and consistent, and in recent years, these methods have been modified and processed for improvement. Some of the methods are briefly described as under.

\section{DPPH method}

The method DPPH free radical scavenging assay was first illustrated in 1958 by Blois, and later on, it was modified to some extent by various researchers. For plant samples, it is one of the most comprehensively used assays to measure antioxidant ability of natural products. This method depends on the scavenging ability of DPPH through adding up an antioxidant or a radical species into the DPPH solution, resulted in the decolorization of that solution. It is most stable free radical scavenger that reacts with substances and can provide a hydrogen atom. Then, the antioxidant activity is calculated by reducing in absorption at $515 \mathrm{~nm}$. This method has been done by preparing the DPPH $(0.1 \mathrm{mM})$ solution in methanol, and then, the prepared solution of $4 \mathrm{ml}$ is supplemented to $1 \mathrm{ml}$ of the sample solution in methanol changing concentrations. The absorbance of the mixture is then calculated at $517 \mathrm{~nm}$ after $30 \mathrm{~min}$. The absorbance of the mixture decreased on large scale suggests considerable free radical trapping ability of the compound [7].

\section{ABTS radical scavenging method}

This method was first developed in 1994 by Rice-Evans and Miller; later on, it was modified in 1999 by Re et al. This modification is based on Metmyoglobin activation by adding hydrogen peroxide and $\mathrm{ABTS}^{\circ+}$ to generate a radical cation. Through the reaction of ABTS and potassium persulfate, this improved process produces a blue-green $\mathrm{ABTS}^{\circ+}$ chromophore and is now extensively used. The ABTS radical scavenging method besides DPPH method is one of the comprehensively used antioxidant methods for plant products. The reduction of ABTS to ABTS radical cation in the presence of potassium persulfate is measured at $734 \mathrm{~nm}$ spectrophotometrically. This method is used for the calculation of total antioxidant ability of hydrophilic as well as lipophilic substances. The antioxidant concentration effect and duration of radical cation inhibition should be kept in mind at the time of determination of antioxidant activity of the sample. Trolox, 6-hydroxy-2,5,7,8-tetramethylchroman-2-carboxylic acid, an analog of the Vitamin E is a water soluble applied as a positive entity, and the antioxidant activity is communicated in terms of trolox-equivalent antioxidant capacity/mg of the extract [7].

\section{Reducing power assay}

The antioxidant activity of the plant extracts is resolved by the method known as reducing power method [26]. In this method, the extract in $1 \mathrm{ml}$ of methanol is mingled with $5 \mathrm{ml}$ of phosphate buffer $(0.2 \mathrm{M})$ at $\mathrm{pH} 6.6$ and $5 \mathrm{ml}$ of $1 \%$ potassium ferricyanide and then incubated the mixture for $20 \mathrm{~min}$ at $50^{\circ} \mathrm{C}$. After that $5 \mathrm{ml}$ of $10 \%$ trichloroacetic acid was added and centrifuged the reaction mixture for $10 \mathrm{~min}$. at 3000 $\mathrm{rpm}$. Then, $5 \mathrm{ml}$ of the solution from the upper layer is mixed with $1 \mathrm{ml}$ of $1 \%$ ferric chloride and $5 \mathrm{ml}$ distilled water, and at $700 \mathrm{~nm}$, absorbance is calculated. A powerful absorbance signifies the amplified reducing power.

\section{FTC method}

The total phenolic content of the plant sample is determined by the FTC reagent assay [28] in a simple and inexpensive way. Although without any methodical optimization or justification, several modifications were made since from years. In this method, $0.2 \mathrm{ml}$ of the plant sample is intermingled with diluted $0.5 \mathrm{ml}$ of FTC reagent. Before the addition of $0.2 \mathrm{ml}$ of saturated solution of sodium carbonate, the mixture is kept at $25^{\circ} \mathrm{C}$ for $3 \mathrm{~min}$. The reaction mixture is then allowed to stand for another $120 \mathrm{~min}$ and the absorbance of the mixture is measured at $727 \mathrm{~nm}$. Calibration curve is obtained by the use of standard, i.e., gallic acid. The total phenolic amount of the sample is expressed in terms of gallic acid equivalents in $\mathrm{mM} / \mathrm{l}$ of sample.

\section{SOME MEDICINAL PLANTS WITH ANTIOXIDANT PROPERTIES}

Since ancient times, utilization of medicinal plant and their products has improved due to their exerted advantageous properties such as antioxidant, hypolipidemic, hypoglycemic, and anticancer activities. Some of the plants with potent antioxidant activities are discussed below:

\section{Zingiber officinale}

Ginger (Z. officinale L.) belonging to the family Zingiberaceae is a perennial herb and has been utilized as a spice for more than 2000 years [29]. In numerous parts of the world, it is not only one of the commonly used species to increase the flavor and taste of the food but also a variety of prospective bioactive compounds is also found with effective pharmaceutical and biological properties. Mostly rhizomes of the ginger are used as a condiment and spice [30,31]. Ginger consumption has been reported to be fruitful in various stress-associated health circumstances, and among such problems, some of them include tumor progression [32], hypertension [33], diabetes-provoked renal, and pancreatic ailments [34]. In conventional system of medicine, it has been used against headaches, colds, nausea, arthritis, and muscular and rheumatic chaos [35]. In addition, it has also been proposed that bioactive compounds from ginger showed various properties including renoprotective [36], anticancer, anti-inflammatory [37], and antioxidant effects [38] are actually antioxidants.

In mammalian system, the antioxidant activity of the compounds from this spice involves only single or more than one process from, free radical scavenging activity, improving the antioxidant molecules in tissues, LPO suppression, reducing the inducible nitric oxide synthase activity, rousing the actions of endogenous antioxidant enzymes, hindering the oxidation of low-density lipoprotein (LDL), and reduction of the enzymes such as 2-cyclooxygenase enzymes and 5-lipoxygenase for metabolism of arachidonate [39].

The astringent compounds of ginger such as 6-paradol and 6-gingerol acquire anti-inflammatory and antioxidative properties. The antioxidant activity has been studied by in vitro due to the presence of total phenols in the extracts of ginger. The antioxidant effect of total phenols of ginger in which DPPH free radical scavenging surpassed to that of BHT and half maximal inhibitory concentration 
(IC50) values for DPPH inhibition was $0.64 / \mu \mathrm{g} / \mathrm{mL}$. The extract from ginger reduced the hydroxyl radicals to an amount greater than that of quercetin which is a potent antioxidant compound. 6-gingerol has chemoprotective and chemopreventive assets which are frequently related to that of anti-inflammatory and antioxidant properties, and it is a scavenger of peroxyl free radicals. Phospholipid liposomes peroxidation decreased due to gingerol in the presence of ascorbate and iron ions $\left(\mathrm{Fe}^{3+}\right)$.Nitric oxide, a reactive nitrogen species, has been concerned to manipulate transduction signal and causes damage to DNA resulting in cancer development, but 6-gingerol is proved to be a strong inhibitor of synthesis of $\mathrm{NO}$ and is also a valuable defender against damage in lipopolysaccharide activated macrophages mediated by peroxynitrite [40-43].

\section{Momordica charantia}

M. charantia L. (bitter gourd) ) from the family Cucurbitaceae has been used in food and medicine from prehistoric times. M. charantia is also known by other names such as karela and balsam pear, and Mara in Thai. It grows in Africa, USA, Malaysia, Indian tropical and subtropical parts, the Middle East, and Thailand [44]. Many advantageous bioactive compounds have been isolated from this nutrient-rich plant, which showed number of powerful pharmacological activities such as antibacterial, antiviral, and anticancer [45,46]. In addition to this, it has strong anti-obesity, hypolipidemic, and antioxidant properties [47]. In one of the studies, the two extracts of M. charantia, using water and ethanol solvents, showed that both these extracts, i.e., water extract as well as ethanol extract possess strong DPPH radical scavenging activity as compared to Vitamin E, used as standard. The IC50 $1 / 4$ values for water extract, ethanol extract, and Vitamin E were $129.94 \mathrm{mg} / \mathrm{ml}, 156.78 \mathrm{mg} /$ $\mathrm{ml}$, and possess potent $172.21 \mathrm{mg} / \mathrm{ml}$, respectively. In addition, these two extracts of bitter gourd showed a superior iron chelating activity in comparison to Vitamin E. In water extract of M. charantia, there is higher amount $(62.0 \mathrm{mg} / \mathrm{g})$ of total flavonoid content than ethanol extract $(44.0 \mathrm{mg} / \mathrm{g})$, and lesser total phenol content is found in water extract $(51.6 \mathrm{mg} / \mathrm{g})$ than ethanol extract $(68.8 \mathrm{mg} / \mathrm{g})$, but both these extracts of M. charantia possessed a strong antioxidant and free radical scavenging properties [48].

\section{Cymbopogon citratus}

C. citratus (DC.) also called as lemongrass from the Gramineae family, a plant cultivated in nearly all tropical and subtropical realms as a source of fundamental oils. In Peru, lemongrass is utilized in the preparation of soft drinks and is also used as a pleasant-tasting, aromatic herbal tea in all the areas where it is to be distributed. The decoction or concoction of its above ground parts has extensive use in traditional medicine. This plant is being suggested to cure disorders of digestive system such as nervous disorders, fever, inflammation, diabetes, and other health troubles [49].

It has been reported that the essential oil isolated from lemon grass has been used as a potential anti-inflammatory and antioxidant agent. To identify the functional groups present in the oil of this plant, FT-IR spectroscopic analysis has been done, which indicated the presence of functional groups such as $\mathrm{O}-\mathrm{H}$ stretching, $\mathrm{H}$-bonded, $\mathrm{N}-\mathrm{H}$ stretching, $-\mathrm{C}=\mathrm{C}$-stretching, aldehyde/Ketone- $\mathrm{C}=\mathrm{O}$ stretching, $-\mathrm{C}-\mathrm{H}$ in plane bending, and -CH3 bending. When compared to L-ascorbic acid (standard), lemon grass in different concentrations showed strong antioxidant activity against the modified LDL provoked cytotoxicity in peripheral blood mononuclear cells. This suggests that lemon grass is a promising antioxidant agent [50].

Another experimental study on lemon grass revealed that it contains the bioactive compounds such as caffeic acid, isoscoparin, isoorientin, isoorientin 2"-0-rhamnoside, swertiajaponin, chlorogenic acid, and orientin which were identified spectroscopically. In this study, two extracts of this plants were extracted, methanol and methanol/ water, and were measured for effects of free radical scavenging using the methods such as 1,1-diphenyl-2-picryl-hydrazyl (DPPH) radical, enzyme xanthine oxidase (XO) inhibition, superoxide anion scavenging, and also human erythrocyte LPO. The results obtained from the above said extracts showed effects in the DPPH radical essay and superoxide anion assay, and the values obtained ranging between 40 and $68 \%$ at $33 \mu \mathrm{g} / \mathrm{mL}$ and $15-32 \%$ at $50 \mu \mathrm{g} / \mathrm{mL}$ in erythrocytes. These extracts also take part in reducing the LPO, with values ranging between 19 and $71 \%$, in the concentration of $500 \mu \mathrm{g} / \mathrm{mL}$, but not showing any effect toward the $\mathrm{XO}$ at $50 \mu \mathrm{g} / \mathrm{mL}$. In all the essays of antioxidant activity, methanol extract was the most effective [51].

\section{Adiantum capillus-veneris}

A. capillus-veneris also known as southern maidenhair fern belonging to the family Adiantaceae is one of the most important species and has been reported to have potential significance for nutritive and medicinal purposes. It has reported a number of bioactive compounds including carbohydrates, flavonoids, carotenoids, triterpenoids, alicyclics, and aoleananes. Due to the presence of these chemical constituents, this plant exerted various pharmacological activities such as anti-inflammatory, antiproliferative, analgesic, antimicrobial, neuroprotective, antioxidant, and many more [52].

It has been reported that the ethanol extract of $A$. capillus veneris showed excellent antioxidant activity in comparison to ascorbic acid used as a standard. It shows low IC50values for DPPH assay and ABTS assay as $0.3986 \mathrm{mg} / \mathrm{gm}$ and $0.695 \mathrm{mg} / \mathrm{gm}$, respectively. The outcomes achieved signified that leaves of $A$. capillus-veneris were endowed with free radical scavenging compounds and can be used as a prospective resource of nutrients and natural antioxidants [53].

Another study on A. capillus veneris revealed that the flavonoids extracted from this plant showed antioxidant activity both by in vitro and in vivo methods. When compared with synthetic antioxidants such as ethylenediaminetetraacetic acid, BHT, and ascorbic acid, the flavonoids of adiantum were estimated in scavenging abilities of superoxide anion, 1, 1-diphenyl 1-2-picryl-hydrazyl (DPPH) free radical, chelating potential of ferrous ion, and reducing power in vitro. The results showed approximate or significant antioxidant activity of flavonoids of adiantum in appropriate concentrations than that of synthetic antioxidants. In vivo activity of flavonoids of adiantum were also examined through acute mice liver injury experiment. In mice, the liver under the influence of CCl4 demonstrated a major decrease in superoxide dismutase (SOD), glutathione (GSH), and catalase levels, but at the same time, considerable enhancement occurs in malondialdehyde (MDA) levels. Compared with the Group II that received only $\mathrm{CCl}_{4}$, the group that received Vitamin $\mathrm{E}$ and higher dose of flavonoids of adiantum showed considerable increase in SOD, GSH, and SOD activity, but simultaneously decreased the MDA activity. The whole process takes place in a dose-dependent manner, and the results obtained showed that the flavonoids of adiantum possess strong antioxidant activities [54].

\section{Stevia rebaudiana}

S. rebaudiana (Bert.), commonly known as candy leaf, sweetleaf, or sugar leaf belonging to the family Asteraceae, is a wild perennial herbaceous plant grows in sandy soil and is native to Paraguay [55]. Stevioside is the chief sweet compound extracted from the $S$. rebaudiana leaves [56]. Its sweetener components have been advocated to possess advantageous consequences on human health in such a way that they show antihuman rotavirus activities, glucose metabolism, antihyperglycemic noncariogenic [57], antihypertensive [58], and antioxidant properties [59]. In rats, the aqueous extracts of dried leaves of this plant provoke systemic and renal vasodilation results in natriuresis, dieresis, and hypotension in rats [60].

The antioxidant activity of dried leaves of S. rebaudiana extract has been studied by measuring DPPH radical scavenging essay, using in different concentrations in increasing order, i.e., 20, 40, 50, 100, and $200 \mu \mathrm{g} / \mathrm{ml}$ in a dose-dependent way, and it ranges from 40.00 to $72.37 \%$, in which it is $64.26-82.58 \%$ for ascorbic acid which was used as standard compound. The aqueous extract has $83.45 \mu \mathrm{g} / \mathrm{ml}$ IC50 
values which is $26.75 \mu \mathrm{g} / \mathrm{ml}$ for ascorbic acid in DPPH assay. The total phenolic content of this extract is measured by using FTC reagent which contained phenolic content in the concentration of $56.73 \mathrm{mg} / \mathrm{g}$ and is found to be extensively effective when compared to gallic acid which is used as reference standard. This extract reduced superoxide anions, hydroxyl radical, and nitric oxide as well with IC50 values 100.86, 100.86 , and $98.73 \mu \mathrm{g} / \mathrm{ml}$, respectively. The presence of greater quantity of phenolic compounds in the aqueous leaf extracts of S. rebaudiana showed its more powerful radical scavenging properties [59].

\section{Datura fastuosa}

D. fastuosa is commonly known by many names. It is an annual herbaceous plant belonging to the family Solanaceae. The various parts such as leaves, roots, and flowers in dried form have been used for epilepsy, skin diseases, wounds and burns, hemorrhoids, diarrhea, rheumatic pains, skin ulcers, hysteria, and painful menstruation. In Ayurvedic system of medicine, this plant has been considered to be bitter, narcotic, astringent, antiseptic, germicide, acrid, anodyne, and sedative $[61,62]$.

The antioxidant activity of $D$. fastuosa was evaluated from the methanolic and hydroalcoholic seed extracts by measuring the total antioxidant capacity and total flavonoid, phenolic, proanthocyanidines, and flavonol contents. The IC50 was $28.34 \mu \mathrm{g} / \mathrm{ml}$ and $25.78 \mu \mathrm{g} / \mathrm{ml}$ of the methanolic and hydroalcoholic extracts of $D$. fastuosa, respectively, through DPPH essay. On behalf of methanolic extract of D. fastuosa, it has been found that the entire antioxidant ability, total amount of flavonoid content, total proanthocyanidines content, total phenolic content, and total amount of flavonol were $6.83 \mathrm{mg} / \mathrm{g}, 6.34 \mathrm{mg} / \mathrm{g}$, $1.42 \mathrm{mg} / \mathrm{g}, 9.97 \mathrm{mg} / \mathrm{g}$, and $5.37 \mathrm{mg} / \mathrm{g}$, respectively, and the values for such parameters of hydroalcoholic extracts were $7.44 \mathrm{mg} / \mathrm{g}, 9.35 \mathrm{mg} / \mathrm{g}$, $0.88 \mathrm{mg} / \mathrm{g}, 6.88 \mathrm{mg} / \mathrm{g}$, and $5.36 \mathrm{mg} / \mathrm{g}$, respectively [63].

The Datura metel leaves were also evaluated for antioxidant activity using different solvents such as methanol, chloroform, ethyl acetate, and n-hexane for extraction process, and the leaf extracts were used for DPPH radical scavenging assay, reducing power assay, total amount of phenolic content, hydroxyl radical scavenging activity, and bleaching activity of $\beta$-carotene. The antioxidant activity was executed at four concentrations sorting from 25 to $100 \mathrm{mg} / \mathrm{ml}$. Among all the leaf extracts of $D$. metel, the chloroform leaf extract showed utmost antioxidant activity by increasing concentrations [64].

\section{Teucrium polium}

T. polium L. Popularly known as felty germander, belonging to the family Lamiaceae, is a natural flower species composed of various numbers of species with credulous antioxidant activity. The leaves and flowers of this plant in combination are used as a rejuvenating infusion. This mixture is also used against diarrhea, gastrointestinal diseases, colds, fevers, stomach pains, and liver ailments. In view of said reference, the above ground part of this plant has been extracted with different solvents, such as petroleum ether, methanol, chloroform, and water. The flavonoids with antioxidant activity were isolated from the methanol extract, which were recognized as apigenin, 4-,7-dimethoxy apigenin, 3-,6-dimethoxy apigenin, and rutin having IC50 values as $30.3 \pm 2.1 \mu \mathrm{g} /$ $\mathrm{ml}, 37.4 \pm 3.4 \mu \mathrm{g} / \mathrm{ml}, 31.5 \pm 3.4 \mu \mathrm{g} / \mathrm{ml}$ and $23.7 \pm 1.9 \mu \mathrm{g} / \mathrm{ml}$ respectively in DPPH assay.. For methanol extract, the IC50 value for DPPH essay was $20.1 \pm 1.7 \mu \mathrm{g} / \mathrm{ml}$, which is same as that of a synthetic compound BHT, used as antioxidant, having IC50 value as $(18.3 \pm 1.9 \mu \mathrm{g} / \mathrm{ml})$. The presence of affluent content of flavonoids, showing great antioxidant activity, in the extract of T. polium was used in many food substances as an alternative of synthetic antioxidants [65].

It has also been studied that the T. polium ethanol extract showed the effective antioxidant activity, same as that of $\alpha$-tocopherol. Recently, the antioxidant activity was also studied on rats by in vivo method, where rats have been delighted with extracts of T. polium, which showed a considerable antioxidant activity as that of $\alpha$-tocopherol (positive control) in the DPPH test. At the doses of $50 \mathrm{mg} / \mathrm{kg}$ and $100 \mathrm{mg} / \mathrm{kg}$, the extracts of T. polium extensively amplified the total antioxidant power and reduced the thiobarbituric acid reactive substances in

Table 1: Some medicinal plants with antioxidant properties

\begin{tabular}{|c|c|c|c|c|}
\hline Plant name & Common name & Family & Part used & References \\
\hline Zingiber officinale & Ginger & Zingiberaceae & Rhizome & [37] \\
\hline Momordica charantia & Bitter gourd & Cucurbitaceae & Whole plant & [48] \\
\hline Cymbopogon citrates & Lemon grass & Gramineae & Aerial part, leaves & {$[51,50]$} \\
\hline Adiantum capillus-veneris & Southern maidenhair fern & Adiantaceae & Whole plant & [54] \\
\hline Datura metel & Datura & Solanaceae & Leaves & [64] \\
\hline Teucrium polium & Felty germander & Lamiaceae & Aerial part & [65] \\
\hline Polyalthia cerasoides & Cherry ashok & Annonaceae & Stem bark & [70] \\
\hline Curcuma longa & Turmeric & Zingiberaceae & Rhizome & [72] \\
\hline Azadirachta indica & Neem & Meliaceae & Leaf & [73] \\
\hline Ocimum sanctum & Tulsi & Lamiaceae & Leaf & [74] \\
\hline Terminalia bellerica & Behda & Combretaceae & Fruit & [75] \\
\hline Solanum tuberosum & Potato & Solanaceae & Tuber & [76] \\
\hline Foeniculum vulgare & Saunf & Apiaceae & Seed oil & [77] \\
\hline Cuscuta reflexa & Akashabela & Convolvulaceae & Stem & [78] \\
\hline Salvia officinalis & Common sage & Lamiaceae & Root & [79] \\
\hline Cinnamomum tamala & Tejpat & Lauraceae & Leave oil & [82] \\
\hline Allium sativum & Garlic & Amaryllidaceae & Bulb & [83] \\
\hline Allium сера & Onion & Amaryllidaceae & Bulb & [83] \\
\hline Costus pictus & Spiral ginger & Costaceae & Leaves & [84] \\
\hline Bacopa monnieri & Brahmi & Scrophulariaceae & Leaves & {$[85]$} \\
\hline Plantago asiatica & Chinese plantain & Plantaginaceae & Seed & [86] \\
\hline Arnebia benthamii & Gaozaban & Boraginaceae & Whole plant & {$[87]$} \\
\hline Aloe vera & Star cactus/Indian aloe & Asphodelaceae & Leaves & [88] \\
\hline Daucus carota & Carrot & Apiaceae & Root & [89] \\
\hline Mentha Pulegium & Pennyroyal & Lamiaceae & Leaves & [90] \\
\hline Cotinus coggygria & Smoke tree & Anacardiaceae & Leaves & [91] \\
\hline Tamus communis & Black Bryony & Dioscoreaceae & Root & [92] \\
\hline Aegle marmelos & Bengal quince & Rutaceae & Fruit & [93] \\
\hline
\end{tabular}


rats, compared to the control [66]. In vitro studies of aqueous extract of T. polium can also efficiently reduce oxidative progressions with significant antioxidant activity [67]

\section{Polyalthia cerasoides}

P. cerasoides (Roxb.) commonly known as cherry ashok, belonging to the family Annonaceae, is a medium-sized evergreen tree found in about all the Deccan Indian forests at an altitude of about $3000 \mathrm{ft}$. The fruits of this plant have been used as food in tribal people of Indian states such as Andhra Pradesh and Tamil Nadu, while as African tribal people consumed the leaves, fruits, and roots of this plant, used to heal rheumatism, aphrodisiac, toothache, and deparasitant, and also used as an anti-inflammatory agent. The stem bark of $P$. cerasoides has been confirmed after various pharmacological investigations reduced the brain stress $[68,69]$.

The antioxidant probability of alcohol extract of stem bark of $P$. cerasoides has been estimated using different essays including DPPH assay, superoxide anion scavenging assay, hydroxyl radical assay, and reducing power assay. The methanolic extract of stem bark of this plant displayed a momentous DPPH scavenging activity inhibition in a dosedependent manner. 50\% inhibition showed at $25 \mu \mathrm{g} / \mathrm{ml}$ concentration corresponding to tannic acid. In superoxide anion scavenging assay, the alcoholic extract acquires the efficiency of $50 \%$ inhibition at the concentration of $80 \mu \mathrm{g} / \mathrm{ml}$ corresponding to tannic acid indicated by the decrease in the absorbance of the plant extract at $560 \mathrm{~nm}$. For hydroxyl radical, the alcoholic extract showed $50 \%$ inhibition, in the concentration of $50 \mu \mathrm{g} / \mathrm{ml}$ corresponding to tannic acid. This extract can also reduce the $\mathrm{Fe} 3+$ to $\mathrm{Fe} 2$ +ions. The total amount of phenolic content in the alcoholic extract of this plant was articulated as $0.589 \mu \mathrm{g}$ of tannic acid comparable to per mg of extract. In all the in vitro antioxidant tests, the stem bark extract of $P$. cerasoides confirmed considerable ROS scavenging activity and restrained elevated amount of total phenolic levels [70].

\section{CONCLUSION}

Cellular harm of human body comes up from free radicals or ROS and appears a basic mechanism, involving a number of neurodegenerative chaos, digestive system disorders, inflammation, diabetes, viral infections, and autoimmune pathologies. From various laboratory experiments, it has been shown that free radicals and ROS are involved in these dreadful diseases. A variety of synthetic antioxidants are used in processed foods to defeat such ailments, but they show evidences of adverse side effects in humans. Several home-grown antioxidants may be valuable in preventing such effects of oxidative stress and have led to substantial attention in manipulating the antioxidant capability of botanicals, foods, and other nutritional antioxidant supplements. In the present study, some medicinal plants as shown in Table 1 , for example, Z. officinale, M. charantia, C. citrates, A. capillus-veneris, D. metel, T. polium, P. cerasoides, C. sativus, C. longa, and A. Indica have been proved to possess valuable antioxidant properties as they contain a large number of secondary metabolites such as flavonoids and phenolics. In addition to antioxidant activity, these compounds are also used as anticarcinogenic, anti-inflammatory, antibacterial, antiviral and antifungal, antispasmodic, and antidiabetic

\section{CONFLICT OF INTEREST}

The authors declared that they had no conflicts of interests.

\section{REFERENCES}

1. Embuscado ME. Spices and herbs: Natural sources of antioxidants-a mini review. J Funct Foods 2015;18:811-9

2. Haworth JE. Natural Antioxidants Review. In: Proceedings of the 56 ${ }^{\text {th }}$ Reciprocal Meats Conference; 2003. p. 95-8.

3. Cai Y, Luo Q, Sun M, Corke H. Antioxidant activity and phenolic compounds of 112 traditional Chinese medicinal plants associated with anticancer. Life Sci 2004;74:2157-84.

4. Patil SM, Kadam VJ, Ghosh R. In vitro antioxidant activity of methanolic extract of stem bark of Gmelina arborea Roxb. (Verbenaceae). Int J Pharm Tech Res 2009;1:1408-84

5. Subedi L, Timalsena S, Duwadi P, Thapa R, Paudel A, Parajuli K, et al. Antioxidant activity and phenol and flavonoid contents of eight medicinal plants from western Nepal. J Tradit Chin Med 2014;34:584- 90

6. Köksal E, Bursal E, Gülçin İ, Korkmaz M, Cağlayan C, Gören AC, et al. Antioxidant activity and polyphenol content of Turkish thyme (Thymus vulgaris) monitored by liquid chromatography and tandem mass spectrometry. Int J Food Properties 2017;20:514-25.

7. Krishnaiah D, Sarbatly R, Nithyanandam R. A review of the antioxidant potential of medicinal plant species. Food Bioprod Process 2011;89:217- 33

8. Leaves L. Antioxidant activity by DPPH radical scavenging method of ageratum conyzoides. Am J Ethnomed 2014; 1:244-9.

9. de Fátima A, Modolo LV, Conegero LS, Pilli RA, Ferreira CV, Kohn LK, et al. Styryl lactones and their derivatives: Biological activities, mechanisms of action and potential leads for drug design. Curr Med Chem 2006;13:3371-84.

10. Shahidi F, McDonald J, Chandrasekara A, Zhong Y. Phytochemicals of foods, beverages and fruit vinegars: Chemistry and health effects. Asia Pac J Clin Nutr 2008;17 Suppl 1:380-2.

11. Auddy B, Ferreira M, Blasina F, Lafon L, Arredondo F, Dajas F, et al. Screening of antioxidant activity of three Indian medicinal plants, traditionally used for the management of neurodegenerative diseases. J Ethnopharmacol 2003;84:131-8.

12. Samuelson G. Drugs of Natural Origin: A Textbook of Pharmacognosy. $4^{\text {th }}$ ed. Stockholm: Swedish Pharmaceutical Press; 1999.

13. Craig WJ. Health-promoting properties of common herbs. Am J Clin Nutr 1999;70:491S-499S.

14. Lobo V, Patil A, Phatak A, Chandra N. Free radicals, antioxidants and functional foods: Impact on human health. Pharmacogn Rev 2010;4:118-26.

15. Chung KT, Wong TY, Wei CI, Huang YW, Lin Y. Tannins and human health: A review. Crit Rev Food Sci Nutr 1998;38:421-64.

16. Hatano T, Kagawa H, Yasuhara T, Okuda T. Two new flavonoids and other constituents in licorice root: Their relative astringency and radical scavenging effects. Chem Pharm Bull (Tokyo) 1988;36:2090-7.

17. Benzie IF, Szeto YT. Total antioxidant capacity of teas by the ferric reducing/antioxidant power assay. J Agric Food Chem 1999;47:633-6.

18. Silva EM, Souza JN, Rogez H, Rees JF, Larondelle Y. Antioxidant activities and polyphenolic contents of fifteen selected plant species from the Amazonian region. Food Chem 2007;101:1012-8.

19. Leontowicz H, Gorinstein S, Lojek A, Leontowicz M, Ci;z M, Soliva-Fortuny $\mathrm{R}$, et al. Comparative content of some bioactive compounds in apples, peaches and pears and their influence on lipids and antioxidant capacity in rats. J Nutr Biochem 2002;13:603-10.

20. Ramos A, Rivero R, Victoria MC, Visozo A, Piloto J, García A, et al. Assessment of mutagenicity in Parthenium hysterophorus L. J Ethnopharmacol 2001;77:25-30.

21. Kirby AJ, Schmidt RJ. The antioxidant activity of Chinese herbs for eczema and of placebo herbs-I. J Ethnopharmacol 1997;56:103-8.

22. Rice-Evans C, Miller NJ. 241 Total antioxidant status in plasma and body fluids. Methods Enzymol 1994;234:279-93.

23. Baltrušaitytė V, Venskutonis PR, Ceksterytė V. Radical scavenging activity of different floral origin honey and beebread phenolic extracts. Food Chem 2007;101:502-14.

24. Halliwell B, Gutteridge JM, Aruoma OI. The deoxyribose method: A simple "test-tube" assay for determination of rate constants for reactions of hydroxyl radicals. Analy Biochem 1987;165:215-9.

25. Jodynis-Liebert J, Murias M, Błoszyk E. Effect of several sesquiterpene lactones on lipid peroxidation and glutathione level. Planta Med $1999 ; 65: 320-4$

26. Oyaizu M. Studies on product of browing effect reaction prepared from glucose amine. J Nutr 1986;44:307-15.

27. Mackeen MM, Ali AM, Lajis NH, Kawazu K, Hassan Z, Amran M, et al. Antimicrobial, antioxidant, antitumour-promoting and cytotoxic activities of different plant part extracts of Garcinia atroviridis griff. Ex T. Anders. J Ethnopharmacol 2000;72:395-402.

28. Singleton VL, Rossi JA. Colorimetry of total phenolics with phosphomolybdic-phosphotungstic acid reagents. Am J Enol Vitic 1965; $16: 144-58$.

29. Bartley JP, Jacobs AL. Effects of drying on flavour compounds in Australian-grown ginger (Zingiber officinale). J Sci Food Agric 2000;80:209-15.

30. Peter KV, editor. Handbook of Herbs and Spices. Cambridge: Woodhead Publishing; 2006. p. 25. 
31. Baliga MS, Haniadka R, Pereira MM, D'Souza JJ, Pallaty PL, Bhat HP, et al. Update on the chemopreventive effects of ginger and its phytochemicals. Crit Rev Food Sci Nutr 2011;51:499-523.

32. Surh YJ, Park KK, Chun KS, Lee LJ, Lee E, Lee SS, et al. Anti-tumorpromoting activities of selected pungent phenolic substances present in ginger. J Environ Pathol Toxicol Oncol 1999;18:131-9.

33. Akinyemi AJ, Ademiluyi AO, Oboh G. Aqueous extracts of two varieties of ginger (Zingiber officinale) inhibit angiotensin I-converting enzyme, iron (II), and sodium nitroprusside-induced lipid peroxidation in the rat heart in vitro. J Med Food 2013;16:641-6.

34. Kazeem MI, Akanji MA, Yakubu MT. Amelioration of pancreatic and renal derangements in streptozotocin-induced diabetic rats by polyphenol extracts of ginger (Zingiber officinale) rhizome. Pathophysiology 2015;22:203-9.

35. Kazeem MI, Akanji MA, Hafizur RM, Choudhary MI. Antiglycation, antioxidant and toxicological potential of polyphenol extracts of alligator pepper, ginger and nutmeg from Nigeria. Asian Pac J Trop Biomed 2012;2:727-32.

36. Mahmoud MF, Diaai AA, Ahmed F. Evaluation of the efficacy of ginger, Arabic gum, and Boswellia in acute and chronic renal failure. Ren Fail 2012;34:73-82.

37. Srinivasan K. Ginger rhizomes (Zingiber officinale): A spice with multiple health beneficial potentials. Pharma Nutr 2017;5:18-28.

38. Nagendra chari KL, Manasa D, Srinivas P, Sowbhagya HB. Enzymeassisted extraction of bioactive compounds from ginger (Zingiber officinale roscoe). Food Chem 2013;139:509-14.

39. Srinivasan K. Antioxidant potential of spices and their active constituents. Crit Rev Food Sci Nutr 2014;54:352-72.

40. Surh Y. Molecular mechanisms of chemopreventive effects of selected dietary and medicinal phenolic substances. Mutat Res 1999;428:305-27.

41. Stoilova I, Krastanov A, Stoyanova A, Denev P, Gargova S. Antioxidant activity of a ginger extract (Zingiber officinale). Food Chem 2007;102:764-70.

42. Aeschbach R, Löliger J, Scott BC, Murcia A, Butler J, Halliwell B, et al. Antioxidant actions of thymol, carvacrol, 6-gingerol, zingerone and hydroxytyrosol. Food Chem Toxicol 1994;32:31-6.

43. Ippoushi K, Azuma K, Ito H, Horie H, Higashio H. [6]-gingerol inhibits nitric oxide synthesis in activated J774.1 mouse macrophages and prevents peroxynitrite-induced oxidation and nitration reactions. Life Sci 2003;73:3427-37.

44. Abd El Sattar El Batran S, El-Gengaihi SE, El Shabrawy OA. Some toxicological studies of Momordica charantia L. On albino rats in normal and alloxan diabetic rats. J Ethnopharmacol 2006;108:236-42.

45. Saeed MK, Shahzadi I, Ahmad I, Ahmad R, Shahzad K, Ashraf M, et al. Nutritional analysis and antioxidant activity of bitter gourd (Momordica charantia) from Pakistan. Pharmacol Online 2010;1:252-60.

46. Sridhar MG, Vinayagamoorthi R, Suyambunathan VA, Bobby Z, Selvaraj N. Bitter gourd (Momordica charantia) improves insulin sensitivity by increasing skeletal muscle insulin-stimulated IRS-1 tyrosine phosphorylation in high-fat-fed rats. Br J Nutr 2008;99:806- 12.

47. Shih CC, Lin CH, Lin WL. Effects of Momordica charantia on insulin resistance and visceral obesity in mice on high-fat diet. Diabetes Res Clin Pract 2008;81:134-43.

48. Wu SJ, Ng LT. Antioxidant and free radical scavenging activities of wild bitter melon (Momordica charantia Linn. Var. Abbreviata Ser.) in Taiwan. LWT Food Sci Technol 2008;41:323-30.

49. Carlini EA, Contar J de DP, Silva-Filho AR, da Silveira-Filho NG, Frochtengarten ML, Bueno OF, et al. Pharmacology of lemongrass (Cymbopogon citratus stapf). I. Effects of teas prepared from the leaves on laboratory animals. J Ethnopharmacol 1986;17:37-64.

50. Jamuna S, Sadullah S, Ashokkumar R, Shanmuganathan G, Mozhi SS. Potential antioxidant and cytoprotective effects of essential oil extracted from Cymbopogon citratus on OxLDL and H2O2 LDL induced human peripheral blood mononuclear cells (PBMC). Food Sci Hum Wellness 2017;6:60-9

51. Cheel J, Theoduloz C, Rodríguez J, Schmeda-Hirschmann G. Free radical scavengers and antioxidants from lemongrass (Cymbopogon citratus (DC.) stapf.). J Agric Food Chem 2005;53:2511-7.

52. Al-Snafi AE. The chemical constituents and pharmacological effects of Adiantum capillus-veneris - A review. Asian J Pharm Sci Technol 2015;5:106-11.

53. Rajurkar NS, Gaikwad K. Evaluation of phytochemicals, antioxidant activity and elemental content of Adiantum capillus veneris leaves. J C Pharm Res 2012;4:365-74

54. Jiang MZ, Yan H, Wen Y, Li XM. In vitro and in vivo studies of antioxidant activities of flavonoids from Adiantum capillus-veneris L. Afr J Pharm Pharmacol 2011;5:2079-85.
55. Goenadi DH. Water Tension and Fertilization of Stevia rebaudiana Bertoni on Oxidropudalf soil. Menara perkebunan, Horticulture Abstracts; 1983;54:2882.

56. Geuns JM. Safety of Stevia and stevioside. Recent Res Dev Phytochem 2000;4:75-88

57. Suanarunsawat T, Chaiyabutr N. The effect of stevioside on glucose metabolism in rat. Can J Physiol Pharmacol 1997;75:976-82.

58. Chan P, Tomlinson B, Chen YJ, Liu JC, Hsieh MH, Cheng JT. A double-blind placebo-controlled study of the effectiveness and tolerability of oral stevioside in human hypertension. Br J Clin Pharm 2000;50:215- 20

59. Shukla S, Mehta A, Mehta P, Bajpai VK. Antioxidant ability and total phenolic content of aqueous leaf extract of Stevia rebaudiana bert. Exp Toxicol Pathol 2012;64:807-11.

60. Melis MS. Chronic administration of aqueous extract of Stevia rebaudiana in rats: Renal effects. J Ethnopharmacol 1995;47:129-34.

61. Parrotta JA. Healing Plants of Peninsular India. New York: CABI Publishing; 2001.

62. Al-Snafi AE. Medical importance of Datura fastuosa (syn: Datura metel) and Datura stramonium - A review. IOSR J Pharm 2017;7:43- 58.

63. Dhiman A, La R, Bhan M, Dhiman B, Hooda A. Plebeian assessment of anti-microbial and in vitro antioxidant zest of $D$. fastuosa L. Seeds. J Pharm Sci Innov 2012;1:49-53.

64. Sangeetha S, Deepa M, Sugitha N, Mythili S, Sathiavelu A. Antioxidant activity and phytochemical analysis of Datura metel. Int J Drug Dev Res 2014;6:4

65. Sharififar F, Dehghn-Nudeh G, Mirtajaldini M. Major flavonoids with antioxidant activity from Teucrium polium L. Food Chem 2009; 112:885-8.

66. Hasani P, Yasa N, Vosough-Ghanbari S, Mohammadirad A, Dehghan G, Abdollahi M. In vivo antioxidant potential of Teucrium polium, as compared to $\alpha$-tocopherol. Acta Pharm 2007;57:123-9.

67. Ljubuncic P, Dakwar S, Portnaya I, Cogan U, Azaizeh H, Bomzon A, et al. Aqueous extracts of Teucrium polium possess remarkable antioxidant activity in vitro. Evid Based Complement Alternat Med 2006;3:329-38

68. Padma P, Chansauria JP, Khosa RL, Ray AK. Effect of Annooa muricata and Polyalthia cerasoides on brain neurotransimitters and enzyme monoamine oxidase following cold immobilization stress. J Nat Remedies 2001;1:144-6.

69. Cousins D, Huffman MA. Medicinal properties in the diet of gorillas: An ethno-pharmacological evaluation. Afr Study Monogr 2002;23:65- 89.

70. Ravikumar YS, Mahadevan KM, Kumaraswamy MN, Vaidya VP, Manjunatha H, Kumar V, et al. Antioxidant, cytotoxic and genotoxic evaluation of alcoholic extract of Polyalthia cerasoides (Roxb.) bedd. Environ Toxicol Pharmacol 2008;26:142-6.

71. Kakouri E, Daferera D, Paramithiotis S, Astraka K, Drosinos EH, Polissiou MG. Crocus sativus L. Tepals: The natural source of antioxidant and antimicrobial factors. J Appl Res Med Aromat Plants 2017:4:66-74.

72. Bulus T, David SI, Bilbis LS, Babando A. In vitro antioxidant activity of n-butanol extract of Curcuma longa and its potential to protect erythrocytes membrane against osmotic-induced haemolysis. Sci World J 2017;12:13-7

73. Pandey G, Verma KK, Singh M. Evaluation of phytochemical, antibacterial and free radical scavenging properties of Azadirachta indica (neem) leaves. Int J Pharm Pharm Sci 2014;6:444-7.

74. Yanpallewar SU, Rai S, Kumar M, Acharya SB. Evaluation of antioxidant and neuroprotective effect of Ocimum sanctum on transient cerebral ischemia and long-term cerebral hypoperfusion. Pharmacol Biochem Behav 2004;79:155-64

75. Basu T, Panja S, Ghate NB, Chaudhuri D, Mandal N. Antioxidant and antiproliferative effects of different solvent fractions from Terminalia belerica roxb. Fruit on various cancer cells. Cytotechnology 2017;69:201-16.

76. Bontempo P, Carafa V, Grassi R, Basile A, Tenore GC, Formisano C, et al. Antioxidant, antimicrobial and anti-proliferative activities of Solanum tuberosum L. Var. Vitelotte. Food Chem Toxicol 2013;55:304-12.

77. Abdellaoui M, Kasrati A, El Rhaffari L. The effect of domestication on seed yield, essential oil yield and antioxidant activities of fennel seed (Foeniculum vulgare Mill) grown in Moroccan oasis. J Assoc Arab Univ Basic Appl Sci 2017;24:107-14.

78. Vijikumar S. Cuscuta reflexa Roxb.-A wonderful miracle plant in ethnomedicine. Indian J Nat Sci 2011;976:997.

79. Li Y, Liu H, Han Q, Kong B, Liu Q. Cooperative antioxidative effects of zein hydrolysates with sage (Salvia officinalis) extract in a liposome system. Food Chem 2017;222:74-83. 
80. Arunodaya HS, Krishna V, Shashikumar R, Kumar KG. Antibacterial and antioxidant activities of stem bark essential oil constituents of Litsea glutinosa Cb Rob. Int J Pharm Pharm Sci 2016;8:258-64.

81. Aju BY, Rajalakshmi R, Mini S. Evaluation of antioxidant activity of Murraya koenigii (L.) Spreng using different in vitro methods. J Pharm Phytochem 2017;6:939-42.

82. Heer A, Guleria S, Razdan VK. Chemical composition, antioxidant and antimicrobial activities and characterization of bioactive compounds from essential oil of Cinnamomum tamala grown in north-western Himalaya. J Plant Biochem Biotechnol 2017;26:191-8.

83. Kim S, Kim DB, Jin W, Park J, Yoon W, Lee Y, et al. Comparative studies of bioactive organosulphur compounds and antioxidant activities in garlic (Allium sativum L.), elephant garlic (Allium ampeloprasum L.) and onion (Allium cepa L.). Nat Prod Res 2017;32(10):1193-7.

84. Prejeena V, Suresh SN, Varsha V. Phytochemical screening, antioxidant analysis and antiproliferative effect of Costus pictus d. Don leaf extracts. Int J Recent Adv Multidiscip Res 2017;4:2373-8.

85. Verma M, Kumar A. Antimicrobial and antioxidant activity of whole plant extracts of Bacopa monnieri (1.) pennell. Int J Appl Biol Pharm Tech 2017;8:73.

86. Amakura Y, Yoshimura A, Yoshimura M, Yoshida T. Isolation and characterization of phenolic antioxidants from Plantago herb. Molecules 2012;17:5459-66.
87. Ganie SA, Dar TA, Hamid R, Zargar O, Ul Abeer S, Masood A, et al. In vitro antioxidant and cytotoxic activities of Arnebia benthamii (Wall ex. G. Don): A critically endangered medicinal plant of Kashmir valley. Oxid Med Cell Longev 2014;2014:792574.

88. López Z, Núñez-Jinez G, Avalos-Navarro G, Rivera G, Salazar-Flores J, Ramírez JA, et al. Antioxidant and cytotoxicological effects of Aloe vera food supplements. J Food Qual 2017. Article ID: 7636237, 10 Page.

89. Shyamala BN Jr., Jamuna P. Nutritional content and antioxidant properties of pulp waste from Daucus carota and beta vulgaris. Malays J Nutr 2010;16:397-408.

90. Jain S, Jain DK, Balekar N. In-vivo Antioxidant activity of ethanolic extract of Mentha pulegium leaf against $\mathrm{CCl} 4$ induced toxicity in rats. Asian Pac J Trop Biomed 2012;2:S737-40.

91. Karagöz A, Artun FT, Özcan G, Melikoğlu G, Anıl S, Kültür Ș, et al. In vitro evaluation of antioxidant activity of some plant methanol extracts. Biotechnol Biotechnol Equip 2015;29:1184-9.

92. Fatima Z, Abderrahmane B, Seddik K, Lekhmici A. Antioxidant activity assessment of Tamus communis L. roots. Int J Pharm Pharm Sci 2016;8:64-71.

93. Abdallah IZ, Ibrahim SS, El-Salam A, Nayrouz AS. Evaluation of antidiabetic and antioxidant activity of Aegle marmelos L. correa fruit extract in the diabetic Rats. Egypt J Hosp Med 2017;67:731-41. 